\title{
Local Faith Actors and the Global Compact on Refugees
}

\author{
Heather Wurtz and Olivia Wilkinson
}

ABSTRACT: Power dynamics of global decision-making have meant that local faith actors have not been frequently heard in the context of refugee response. The development of new global refugee and humanitarian frameworks gives hope that there will be greater inclusion of Southern-led, faith-based responses. A closer look, however, demonstrates discrepancies between the frameworks used in global policy processes and the realities of local faith actors in providing refugee assistance. We present primary research from distinct case studies in Mexico and Honduras, which counters much of what is assumed about local faith actors in refugee services and aid. Interventions that are considered to be examples of good practice in the global South are not always congruent with those conceptualized as good practices by the international community. Failure to recognize and integrate approaches and practices from the global South, including those led by actors inspired by faith, will ultimately continue to replicate dominant global power structures.

KEYWORDS: faith-based, global South, Honduras, humanitarianism, localization, Mexico, refugees

\section{Introduction}

This article examines the role of local faith actors in institutional responses to refugees (henceforth refugee response), first in relation to global policy guidelines and frameworks promoted through the Global Compact for Refugees (GCR) affirmed by the UN General Assembly in December 2018, and then in regard to local faith actors' own experiences and reimaginings of policy concepts as relevant to their own contexts. Our contribution is to offer one of the first interpretations of the GCR through the lens of faith-based responses led by people, communities, and organizations situated in what is often referred to as the global South, while recognizing that this is a contested concept with many different perspectives about what constitutes the global South (Fiddian-Qasmiyeh and Daley 2018). We begin by analyzing the GCR through a framework that highlights and deconstructs power inequalities behind Northern perspectives of Southern and local faith responses. We then bring this into conversation with empirical evidence from case studies from Mexico and Honduras, understanding that the location of these countries as part or not part of the global South can be debated. Examining how local actors in these diverse case studies conceptualize the driving objectives and mechanisms of action to respond to displacement reveals a stark divergence from core concepts that undergird international humanitarian paradigms (e.g., technology as innovation, self-reliance as personal responsibility, standards of religious neutrality). Findings expand scholarship that aims to trace 
commonalities and differences across multiple scales of aid provision in order to further nuance understandings of local faith actors in refugee response.

We locate this work within debates on South-South migration and responses that demonstrate the vital need for a "Southern lens" on humanitarian processes (Fiddian-Qasmiyeh 2015; Fiddian-Qasmiyeh and Pacitto 2016). As evidence shows, it is not only the case that 90 percent of displacement occurs through processes of South-South migration (refugees fleeing from one country in the global South and then arriving in another Southern state), but also that responses to displacement are themselves often led and implemented by actors from across the global South, including actors inspired by faith (Fiddian-Qasmiyeh 2018b). However, international aid policies continue to reflect the perspectives and priorities of the global North (Chimni 2018), limiting the potential of more effective solutions to displacement that are grounded in local material conditions and social dynamics.

Over recent years there has been a push for the "localization of aid," an agenda that has been promoted throughout the humanitarian community since the 2016 World Humanitarian Summit. This approach aims to shift resources and power from international actors to local actors in order to strengthen their ability to respond to humanitarian crises at the local level. This has included commitments to improve partnerships with local faith actors (LFAs), such as religious leaders and faith-based organizations (World Humanitarian Summit 2016). LFAs are increasingly recognized for the central role that they play in responding to displaced populations and building community resilience in contexts of crisis (Ager, Fiddian-Qasmiyeh, and Ager 2015; El Nakib and Ager 2015; Fiddian-Qasmiyeh 2011; Wilkinson 2018b; Wilkinson and Ager 2017). In response, the United Nations High Commissioner for Refugees (UNHCR) has made efforts to improve its engagement and collaboration with local faith-based actors, as demonstrated by the 2012 UNHCR convening of the High Commissioner's Dialogue on Faith and Protection.

Despite new initiatives to collaborate with local faith actors, experts in the field contend that effective partnerships are impeded by the pervasive disconnect between the predominantly secular frameworks of international humanitarian organizations and how those frameworks are interpreted by local actors (A. Ager and J. Ager 2015; Ferris 2011; Wilkinson 2017; Wilkinson 2018b). Alastair Ager (2014: 17) asserts that the way humanitarian principles are framed "often shapes humanitarian assistance in a way that is alien to many local faith communities, creating a disconnect with local resources relevant for their recovery from crisis." This is often driven by the international aid community's concerns over neutrality and the perceived risks of proselytization, which hinder the type of mutual understanding and commitment needed to advance collaborative partnerships.

Scholars have increasingly called for recognition by the international humanitarian community that a secular framework reflects a predominantly Western, neoliberal ideology, and is just one of many epistemological perspectives through which to interpret social problems and imagine effective solutions (Wilson 2017). Some scholars even assert that the staunch secular stance upheld by international aid organizations not only impedes inclusion of diverse local actors but may also serve to reproduce cycles of social inequality and oppression, as a new "form of neo-colonialism" (A. Ager and J. Ager 2011: 457). This underscores the need for further elucidation of the frameworks and priorities created and held by local faith actors based in the so-called global South within the context of local realities and resources, and the actions that Southern-based actors take to negotiate, and contest, international humanitarian initiatives.

The presentation of our findings examines concepts of "innovation," "proselytization," and "self-sufficiency" as interpreted and defined by the local faith actors that took part in our study. We chose these areas as they follow from the good practices ${ }^{1}$ for refugee response as defined by UNHCR in relation to the Comprehensive Refugee Response Framework (CRRF), of which the 
GCR is a part, as well as being also defined as contested or important according to the LFA participants in this research. We demonstrate the need for nuanced interventions shaped by locally based interpretations of humanitarian principles. Such insights are essential to shift the criteria for Northern-based funding structures in a way that reflects the actual needs and desires of Southern-based communities affected by and responding to displacement, rather than imposing predetermined standards for what qualifies as optimal modes of intervention. We also argue that this must necessarily include support for local communities to engage in civic and political engagement in order to advocate for changes to their current conditions, since power structures will only continue to be reproduced until the roots of oppression and inequality are challenged and transformed.

\section{Methodology}

In this article, we present findings from a study conducted by the Joint Learning Initiative (JLI) supported by UNHCR, which aimed to identify examples of good practices of refugee response carried out by local faith actors in Mexico and Honduras. As members of the research team for the JLI, our research took place in a bridging space between the international and local. JLI is an international research network connecting with academics and practitioners, and our role in this project was to work through this network to identify and highlight good practices at local levels. Our research question was simply: "What are the roles of local faith actors in refugee response?" Our aim was to detail the complex realities of local faith actors. We examined several contexts situated within the geographic bounds of what is often conceptualized as the global South (Mexico, Honduras, Uganda, Lebanon).

For each case, a country-specific researcher was employed to conduct approximately 30 qualitative interviews and one focus group per site among a range of diverse community stakeholders, including local faith leaders, volunteers, and staff members, international and national organizations, host community members, and displaced people. All interviews were transcribed and then analyzed with NVivo using thematic content analysis to explore how local actors and displaced people themselves describe the benefits of locally based responses to people seeking international protection. For the purposes of this article, we explore the finding emerging from interviews and focus groups with a total of 70 people across the two countries.

The objective of this study was to strengthen critical understandings of how local faith actors understand their own role in humanitarian assistance, according to their own terms, with the goal of disseminating findings to a wide cross-disciplinary and international audience. Through close comparative examination across cases, we began to see the necessity of bringing "local faith actor" stories to light for international decision makers to contend with, in addition to noting the inadequacy of that term when interpreted by the research participants. Our interlocutors would not call themselves "local faith actors" - that is a term created purely for international actors and the frameworks within which they operate. However, as brokers, we need to be cognizant of the many jargons used along the spectrums of local and international response; it remains the key term we use, although we recognize the diversity of actors within that designation.

Although our research questions were designed based on the UNHCR "good practices" framework, we were particularly attentive to how those concepts aligned with or diverged from the perspectives of local faith actors within each distinct context. While this approach generated a rich body of data, we are also aware of its limitations. For instance, the research questions emerged from and data analysis took place within the context of research institutions based in the global North, even if we paid particular attention to our own positionality and aimed to 
maintain a high level of reflexivity about our relationship to the research. In turn, the researchers across the countries had backgrounds from the global North and South, and although they had country-specific expertise, they were not all originally from that country. Indeed, in conducting qualitative research, the researcher must be aware of one's distinct positionality across dimensions of social diversity, such as race, gender, class, and education, and how this may affect interactions and relationships with informants (Berger 2015). As scholars have noted for years, informants and interlocutors may alter what they say and do in response to the presence of the researcher. In effect, researchers encountered varying degrees of trust and suspicion among research interlocutors across all of the research sites. Miscommunication and misunderstandings occurred, particularly in those areas and with those organizations that had previously had negative experiences with other researchers and journalists or mixed relationships with local representatives of UN agencies and other NGOs. Researchers also encountered access issues, including difficulties accessing areas that meant that interviews on occasion were canceled.

Finally, most displaced people (defined as migrants, refugees, and internally displaced people) interviewed for this project were recruited via the organization we were researching in the area. We were creating case studies of an organization, and this group was therefore purposively sampled to gather information particularly about the organization in question. While the researchers stressed their independence from the organizations in question, as recipients of services from the organization, these research participants may have been reluctant to express discontent for diverse reasons. We have maintained participant anonymity and confidentiality in order to mitigate the risk to participants, but this cannot completely remove the fact that our interlocutors may have hesitated to express criticism, and this has been taken into account in the analysis accordingly. We triangulated responses by talking to a cross-segment of society that included refugees and displaced people, host community members, local religious leaders and other community leaders, and NGO staff. This triangulation of information also helped to mitigate bias by demonstrating multiple perspectives.

\section{Analyzing the GCR's Key Concepts in Relation to Faith}

The process toward formulating and adopting the GCR captured the attention of policy makers in New York and Geneva between 2016 and 2018. While it is a nonbinding document, the GCR aims to shape the international response to refugees. There were regional iterations leading to the GCR, such as the San Pedro Sula Declaration, the Nairobi Declaration on Somalia, and the Arab League declaration. These regional interpretations and declarations of support link the GCR to centers of decision making geographically located in the global South. Likewise, the GCR recognizes regional and subregional support, "without prejudice to global support," in paragraphs 28-30. However, the process, in framing the New York declaration as geographically located in the global North, and with consultations that largely took place in Geneva, leaves the GCR as a Northern-led and top-down global policy.

The commitment of the GCR to a multistakeholder, or "whole-of-society," approach is a crucial move toward recognition of the diversity of actors involved in refugee response (Domicelj and Gottardo 2019) that shifts the limelight somewhat away from national governments and international politics to a whole new field of actors that are more regularly and intimately connected to the daily lives of refugees. This list of actors, from international to local levels, includes UNHCR, humanitarian and development actors, the United Nations system, a global academic network, parliaments, public-private partnerships, networks of cities and municipalities, civil society organizations, faith-based actors, local authorities and other local actors ("including 
local community leaders and traditional community governance institutions," GCR, para. 37), sports and cultural activities, and refugees and host community members. These actors are all part of the multistakeholder approach. As local actors and faith-based actors are part of this, the first part of this article analyzes how the GCR conceptualizes local faith actors, and then, in the second part of the article, we trace how this relates to the lived experiences of local faith actors.

While the global South is not mentioned at all in the GCR, terms such as "local" and "subregional" emerge as euphemisms for actors in and from the global South (Fiddian-Qasmiyeh 2018 b). It is a success of the document in many ways that there is a greater recognition of this diversity of actors, but analysis of the way in which these actors-including, in this case, "local actors" ${ }^{2}$ and "faith-based actors" 3 -are described in the GCR demonstrates power imbalances. Local authorities are named first in the GCR multistakeholder list, with "other local actors," as an addendum that has no further clarification. These "other local actors" will presumably have overlap with some of the range of actors listed overall, such as those that are faith-based, cultural, civil society, and sports-related, but that is not recognized. The local actors are recognized as "first responders" that "experience the most significant impact over the medium term," and yet they are still framed as needing support to "strengthen institutional capacities" such as through funding and capacity building. While we need to be wary of the de-responsibilization of international actors and over-responsibilization of local actors, this framing serves to posit that local actors are lacking capacities and need support from international actors without acknowledging that local actors will have many capacities that are not held by international actors and capacity sharing would be a more equitable and collaborative way forward (Jayawickrama and Rehman 2018; Wilkinson 2017). In this light, the GCR still takes the view of international actors as professional and fully capable and local actors as lacking capacity.

Faith-based actors are particularly recognized as assisting in the areas of "conflict prevention, reconciliation, and peacebuilding, as well as other relevant areas." Much scholarship has readily asserted the vital role of faith actors in conflict prevention, reconciliation, and peace building (Garred and Abu-Nimer 2018; Hayward and Marshall 2015; Kubai 2018; Shannahan and Payne 2016), and as such, that assertion is not itself in doubt; however, it must be noted that this is one of the few areas in which conflict prevention is mentioned in the whole document (Sharpe 2018), seemingly leaving it up to the faith actors to simultaneously sort out the root causes of displacement and "build peace." Likewise, the inclusion of the phrase "other relevant areas" is tantalizingly and frustratingly brief and abrupt. In earlier drafts of the GCR (UNHCR 2018) an additional line had been added: "They could also support private sponsorship programmes or other pathways for admission to third countries." This line was removed and subsumed into "other relevant areas."

Given the multitude of "other relevant areas" that are, and have long been, addressed and promoted by faith actors_-including a range presented in the rest of this article ${ }^{4}$-we are left wondering why "other relevant areas" are not specified. The most practical answer is space, in that it was simply too lengthy to list the many and various ways in which faith actors are involved in refugee response, so a catch-all phrase was used. Yet as the GCR is a global policy document with all the power dynamics that entails, we are left to ask who will really define when and by whom faith actors are deemed to be "relevant," leading to the inference that the decisionmaking power is not in the hands of local faith actors. As noted earlier, critiques of international humanitarian actors have argued that there is a secular bias against faith actors (Ager and Ager 2015; Wilkinson 2018a; Wilson 2012) equated to the privatization of faith in the international public sphere in which the GCR exists. Therefore, the fact that faith-based actors are included at all could be seen as a success. However, authors have also warned that there has been a cooption of faith and a perversion of the use of faith in international politics (Hurd 2015) that 
leads to politicized religion (Sullivan et al. 2015) or the instrumentalization of religion (Ager and Ager 2015) to meet goals defined in the global North, and as "a way for Northern states to shift resources, and responsibilities, onto Southern actors, or to simply withdraw from international responsibilities" (Fiddian-Qasmiyeh 2018a).

The combination of the literal "othering" (through discursively constituting "other local actors" and "other relevant areas") in the GCR leaves local faith actors in an inferior position and a gray area of some, but limited, recognition. We are left with the start of an exchange about local faith actors, but little information about how to bring local faith actors into the conversation about their role in the "whole-of-society" approach proposed for the GCR. In order to understand the ways in which local faith actors are operating as part of an already existing "whole-of-society" refugee response and to demonstrate how our interlocutors, including LFAs, define the "other relevant areas" in which they are involved, we now turn to our case studies.

\section{Reimagining Policy Frameworks through the Lens of Local Faith Actors}

Our findings, which draw on two case studies of faith-based responses for refugees in the context of the so-called global South, demonstrate notable discrepancies between best practice frameworks espoused in the GCR and the experiences of local actors. The way that policy concepts are reimagined through local actors' discourse and practices generates novel insight into diverse forms of South-to-South responses to displacement that both complement and challenge "normative" Northern-led approaches (Fiddian-Qasmiyeh 2015). As our findings reveal, the crucial roles that local actors play in these case studies underscores the need to recognize the value of alternative modalities to providing refugee assistance, the priorities that drive local practice, and the reasons why certain approaches work in particular contexts. A deeper understanding of how international policy agendas are taken up and transformed within local contexts is crucial to advancing communication and cooperation across different scales of institutional intervention and refugee support. It is also central to efforts to mitigate North-South power differentials that increasingly shift the burden to South-based actors through a myopic perspective of what kind of support is needed and desired by locally based actors and their communities (Milner 2016).

We use the categorizations of "innovation," "proselytization," and "self-reliance" to structure the analysis of our findings. These areas are included because, first, they represent some of the major themes of the Comprehensive Refugee Response Framework (CRRF), of which the GCR is a part, as well as recent trends in contemporary humanitarian response ("innovation" and "self-reliance"). Second, proselytization remains one of the most pressing concerns for international actors when it comes to partnering with faith actors, and this topic emerged as significant throughout our research findings in a way that was not otherwise recognized in broader humanitarian trends, as it is uniquely associated with faith-based work, even if that is a misleading and reductive association (Lynch and Schwarz 2017).

\section{"Innovation" through Social Inclusion Rather Than Technological Interventions}

Humanitarian innovation has become a trend in recent years, but the latest reports show that there is a growing backlash to "shiny tech" that does little to address structural challenges (Parker 2019). Innovation has an international definition that, as we found in our research, was interpreted very differently by local faith actors. In the international community, innovation is often synonymous with the application of new technologies and strategic approaches within development and communications programming, such as digital network interventions that 
increase connectivity among refugees or experimental organizational funding structures (see, e.g., Parater 2015; UNHCR 2016). While it is important to recognize the value of new practices and ideas that are generated by the (mostly Northern) humanitarian aid community, a myopic scope of the meaning of innovation fails to take into account inventive responses grounded in the local context. For example, in communities in which pervasive violence and discrimination against refugees is the greatest concern, cultural or religious-based interventions, opposed to those driven by technology, may have much more extensive societal reach.

In our study, across countries, when asked about innovation, informants consistently described psychosocial interventions that aim to combat stigma and build emotional and psychological resilience of displaced people, especially among vulnerable populations. This stands in stark contrast to the GCR's overwhelming lack of specific measures to protect the rights of women, children, and other vulnerable categories throughout the entire process of displacement (Chimni 2018). Many of our informants discussed initiatives that aimed to address that gap through recognition of the impact of intersecting dimensions of social inequality, such as focusing on LGBT and young people.

The La 72 migrant and refugee shelter in Tenosique, Tabasco, Mexico, is a prime example. La 72 was founded by the Franciscan order in 2011 to accommodate the overwhelming number of migrants fleeing extreme violence and endemic poverty from the Central American countries of Guatemala, Honduras, and El Salvador. According to internal reports, between 2011 and 2018 the shelter accommodated approximately 80,000 displaced people. Over time, the shelter implemented significant structural and practice-based changes in order to respond to increasing diversity among the displaced population, including a significant rise in the arrival of women, unaccompanied minors, and people from the LGBTQ+ community.

The work of La 72 is guided by a distinct understanding of humanitarian practice that draws upon Franciscan philosophy, as well as a critical stance toward the involvement of both government and international NGOs in migration and refugee responses. The shelter receives no governmental funding; although the shelter collaborates with local UN agencies, they have no signed agreement with international organizations, allowing them to maintain autonomy over the services and resources they provide. In interviews with shelter administrators, La 72 was distinguished from other faith-based organizations by its emphasis on the defense of human rights and respect for religious diversity, rather than being rooted in Christian charity. This reflects a stark divergence from the origins of the Northern-led aid industry and is instead an approach that aligns closely with the principles of liberation theology (a movement that arose in Latin America in the 1950s in response to pervasive social and political inequality; see Gutiérrez 1988). According to the shelter's moral framework, defense of human rights not only entails the provision of basic needs and personal security from violence and harm, but also necessarily includes services that inform migrants about their legal options in Mexico and the United States, and that assist them in completing specific legal procedures for seeking international protection.

Another core component of the shelter's humanitarian approach centers firmly on practices that uphold human dignity and that help to mitigate the emotional and spiritual burden of societal discrimination and degradation of migrants and refugees. As the shelter director articulated: "It's about dignity in its fullest sense. We want that people leave here with their heads held high, with pride, with hope, ready to confront whatever comes before them." Respect for social diversity is critical to this approach and drives interventions focused on specific vulnerable populations that are often underrepresented in other faith-based approaches to migrant and refugee aid.

When asked about innovative practices at La 72, the vast majority of informants described the comprehensive and specialized programming for LGBTQ+ refugees and migrants. Few 
Catholic shelters in Mexico provide LGBTQ+-sensitive services; some even prohibit the entry of LGBTQ+ migrants if they fail to adhere to gender-normative rules and regulations (e.g., "gender-appropriate" clothing). In contrast, La 72 has an explicit LGBTQ+ program, which not only entails the spatial inclusion of LGBTQ+ people through the provision of separate housing quarters, but also a range of affirming events and activities within the shelter and broader community. For example, La 72 carries out LGBTQ+-sponsored workshops; promotes participation and representation of the LGBTQ+ community within religious ceremonies; and provides access to culturally sensitive medical and psychological care. La 72 was the first shelter in Mexico to design and implement an LGBTQ+-specific protocol, and has since garnered significant international accolade for its support of LGBTQ+ migrant rights.

For many LGBTQ+ individuals fleeing their countries due to gender- and sexuality-based violence and persecution, the protective and inclusive shelter environment provides an opportunity to truly embrace their identity and engage in a critical journey of self-discovery. This can be especially powerful for individuals who identify as transgender, as articulated by one of La 72's employees:

To see that transformation, to see someone enter as a gay man and then leave the shelter as a woman ... Here they can start their hormones, start dressing how they like, they can dress and interact like a woman at the parties we have here every Saturday night ... and little by little they take on that identity. To have a space of such freedom ... where they are not discriminated against, not criticized ... where even though it's a Catholic project, they don't have to be afraid.

La 72's drive for inclusion demonstrates their commitment to a "whole person" approach that recognizes the critical importance of upholding human dignity in humanitarian response, in addition to meeting basic needs of shelter, protection, and material provisions.

Similar to La 72's support for LGBTQ+ individuals, local actors in Honduras also discussed innovation in relation to their efforts to help displaced youth restore dignity and self-esteem through long-term engagement and critical dialogue. The Mennonite Social Action Committee (CASM) is a Christian nonprofit organization that runs a locally based program for Honduran youth displaced by gang violence and endemic poverty. Many of the youth who participate in the program have recently returned to Honduras after being deported from Mexico and the United States. In addition to psychological and material assistance, the organization provides three-month-long courses in vocational training and regular formal and informal group discussions about migration, human rights, social inequality, and other related topics. Displaced youth-especially those who have returned following migration-often experience intense feelings of social isolation, failure, stigmatization, and hopelessness. Through a holistic approach that recognizes the need to respond to the social, economic, and psychological facets of youth' lives, CASM fosters the capacity of youth to rewrite their personal narratives and envision future possibilities. In one case, a young woman, who at the start of the program seemed very downcast and introverted, barely spoke in the group sessions. By the end of the program, she demonstrated a renewed sense of self-confidence and a profound understanding of the structural factors that drive migration (rather than an internalized discourse of personal failure). As a CASM volunteer relayed: "She speaks very clearly that that trajectory, from someone who couldn't sleep and couldn't speak to someone who is very articulate and very clear about what should be happening and about what she went through-that she totally credits to the psychosocial support from CASM." Many hosts and CASM staff reported observing various cases of personal transformation among youth. Such a shift in perspective was viewed by informants as crucial to the successful reintegration of displaced youth; to preventing their involvement in 
gang-related activity or return migration; and even to cultivating future leaders and community advocates. For example, as a result of youth participants' petition for additional opportunities to stay involved in the organization and to take a stronger role in policy and advocacy work in their communities, CASM collaborated with the local UNHCR office to form a youth network. The network facilitates weekly training sessions for youth on legal rights, leadership skills, and civic engagement. Through in-depth engagement in the network, youth are given the space and conceptual tools to voice their concerns and propose feasible solutions to key community stakeholders. In November 2018, for instance, the youth network participated in a regional policy forum with government and civil society institutions, community leaders, and private business owners to discuss initiatives to address the lack of meaningful employment opportunities for youth in Honduras.

As these cases demonstrate, when asked about innovation, rather than citing specific technologies or products, local actors described holistic practices that cross humanitarian and development silos, with particular emphasis on combating stigma and building personal resilience. Assumptions about the innovative capacity of certain interventions and resources may cause oversight of the core issues that drive conflict and disparity among displaced populations and, in turn, undermine approaches that actually work according to the resources and dynamics within the local context. As opposed to criticisms of "shiny tech" innovation, these innovations are helping address some of the root causes of psychological distress and address deep-seated discriminatory practices in ways that are culturally relevant precisely because they are engaging with and challenging the existing cultural paradigms around sexuality and migratory status in their own contexts. These are cultural and social innovations that aim to change knowledge about and attitudes toward refugees and migrants.

\section{Neither Proselytization nor Secularization: Alternative Approaches to Integrating Faith in Humanitarian Responses}

Proselytization in humanitarian settings is generally described as efforts made by individuals or faith-based organizations to evangelize or apply undue pressure to bring about religious conversion through the use of humanitarian practices and resources in contexts of crisis (see Ensor 2003 for a more detailed discussion of the intersection of religion and postdisaster response). It is often perceived as antithetical to humanitarian principles of impartiality and neutrality, which influences the types of partnerships and practices that international organizations choose to engage in (Lynch and Schwartz 2017; Marshall 2016). Many international actors avoid collaboration with local faith actors and faith communities precisely because of the fear of how they might use humanitarian responses to advance religious motives. However, as a social construction that emerges from Northern belief systems and circumstances, proselytization is often projected onto Southern contexts without taking into account the nuanced or locally situated dynamics of local faith communities and the people they aim to assist. This precludes a more complex and comprehensive understanding of the role that religious intervention may play in responding to the needs of displaced people across religious affiliations.

Findings from Mexico demonstrate that organizations that provide spiritual guidance in a way that is sensitive to religious diversity can be an important source of social and emotional support for displaced people. Openness to religious diversity also facilitates greater involvement and advocacy of volunteers who may not be religious per se but who share values of social justice and community building. The ability to engage in shared activities and dialogue across religious and cultural divides has important implications for combating xenophobia and promoting social cohesion and integration within local communities. 
In La 72, spiritual support was viewed positively by many of our informants-both refugees and faith leaders-especially when it was perceived as being sensitive to religious diversity and driven more by shared values of respect and compassion than by religious dogma. When asked about religious activities, many informants in La 72 in Mexico applauded the ecumenical, nondenominational approach to spiritual practice, such as the ecumenical service led by the friar every Sunday or the period of silent reflection that occurs every evening after dinner. These practices were adapted to accommodate the diverse religious backgrounds of the displaced population.

Here, there is a profound respect for faith and for the people who reside here. If you go into the chapel, there's not a single religious image, out of respect for the different types of religion that people practice. Here, the shelter is run by the Franciscan order within the Catholic Church, but most of the migrants who come here practice other religions. So, it's very open here, and the friar never makes anyone feel obliged to participate in religious activities, never, never.

The ecumenical approach to spirituality promoted at La 72, with an emphasis on social inclusion and equality, was viewed by many informants as critical to maintaining a strong volunteer base and ongoing support of local community residents. Volunteers came from a variety of religious backgrounds, many identifying as nonreligious and openly discussing critical opinions about religious institutions. However, several reported a significant shift in their perspective of organized religion as a result of their volunteer experience, gaining new insight into the socially transformative potential of faith-based communities that uphold social justice values (such as through the promotion of legal and human rights). As revealed by a La 72 volunteer: "Human dignity comes first, above all, above any particular religious denomination ... We don't want to impose rules or constraints to how people practice faith; we aren't aiming to indoctrinate anyone or to try to convert anyone to the Catholic religion. The main objective is to uphold human dignity and to respond to the urgent needs of the population." Most volunteers and staff members at La 72 recognized the importance of providing religious and spiritual support, especially given the circumstances of hardship and vulnerability that refugees continuously face. They consistently emphasized that the shelter chapel was always available to refugees for prayer and reflection and that mass was held every Sunday for those who wished to attend. Furthermore, every evening before dinner, a local faith actor would lead the group in a brief reflection, followed by a minute of silence to foster a sense of community and shared spirituality.

Responses from staff members working for local faith actors show how they support religion and spirituality without imposing specific religious beliefs and practices. This throws light on a point of tension for international humanitarian actors with local faith actors. If local faith actors are found to be sharing their faith with their beneficiaries, where do the boundaries lie? We would suggest that these findings demonstrate the wide scope of relevant interactions that may occur between local faith actors and beneficiaries, while maintaining a clear distance from proselytization. In partnerships with local faith actors, therefore, it will be highly important for international actors to understand the intricacies of these processes and very clearly define, with concrete examples, their own boundaries on this subject from the outset.

\section{Self-Reliance through Community Solidarity and Collective Action}

Enhancing the self-reliance of displaced people is one of the core objectives of the CRRF and a key priority of the United States Agency for International Development's (USAID) shifting framework for sustainable development (2019). According to UNHCR, self-reliance refers to "the economic and social ability of the individual refugee, household or community to meet 
essential needs in a sustainable manner and with dignity" (2017: n.p.). Self-reliance is facilitated by expanding opportunities for displaced people to access essential social services and resources, like health care, education, language courses, adequate accommodation, and entry into the local labor market, in a way that involves and supports the host community and does not rely on the ongoing assistance of aid organizations.

There are a growing number of critiques of the notion of self-reliance as promulgated by international humanitarian frameworks (Easton-Calabria and Omata 2018). For example, although the GCR recognizes the importance of enhancing self-reliance throughout the entire period of displacement, interventions are often implemented within a narrow window of time immediately prior to or during the process of gaining recognition of refugee status. This reflects a broader international trend in which aid is significantly reduced or cut off in contexts of protracted refugee conditions, particularly when donor communities are pressured to intervene in "high profile refugee crises" (ibid.). The limited scope of self-reliance programs have led scholars to criticize the use of self-reliance rhetoric, which emphasizes notions such as "empowerment" and "agency," while interventions ultimately provide "ways for donors and states to evade their responsibilities towards refugees and a justification to perpetuate structural inequalities that create and maintain particular forms of vulnerability and risk in protracted displacement" (Fiddian-Qasmiyeh 2019: 30; Easton-Calabria and Omata 2018).

Our findings reveal that a focus on the work of local faith leaders and faith communities helps to expand our understanding of self-reliance in ways that go beyond conventional conceptualizations, particularly in terms of reaching those who often fall outside of the limited scope of the "refugee" response of external organizations. The way in which self-reliance is conceptualized by local actors markedly differs from that of large-scale international organizations, which have tended to embrace a neoliberal understanding of self-reliance as something that is achieved through personal responsibility and independence. Evan Easton-Calabria and Naohiko Omata report that this trend "has coincided with a larger neoliberal shift in development from addressing structural factors of poverty and inequality to focusing on individuals' ability to navigate adversities alone" (2018: 1462). In contrast, interventions by many of the local faith actors in our study promote community solidarity, cohesion, and the training and education of local residents. This has been seen in other "Southern" approaches, such as Cuba's model of refugee response that promotes community-level (opposed to individual-level), refugee-refugee self-sufficiency (Fiddian-Qasmiyeh 2011). The support and commitment of local actors who are fully integrated into the social fabric of local communities is crucial to sustaining interventions over time despite shifts in funding and resources.

In both Mexico and Honduras, local networks of assistance for displaced people have been built upon well-established church infrastructure that extends from the central parish to smaller churches and chapels spread across the region. In both cases, religious motivation and a strong commitment to community are key incentives for local residents who voluntarily carry out what is often emotionally exhausting and selfless labor with little financial rewards. Faith-based organizations are often challenged by limited resources and small staff; community volunteer networks are imperative for extending the reach of these organizations in order to meet the needs of displaced populations. Furthermore, in some contexts, community volunteers impart a greater sense of trust in those whom they serve because of their own personal experience in the past with violence and displacement.

In Honduras, for instance, women in local communities who have previously experienced the loss or disappearance of a migrant family member receive crisis intervention training by faith-based organizations so that they can assist women and families undergoing similar experiences. They provide psychosocial support, as well as assistance in navigating complicated 
legal dynamics, such as those pertaining to the repatriation of the body of the deceased. Many of these local actors draw upon faith to guide their labor and to find strength to persevere through trying experiences. As one local faith actor in Honduras shared: "Faith is what carries us through all of the difficulties and challenges of this work: the limitations that we face, the feelings of hopelessness and frustration, you know? So, it gives us strength to keep moving forward despite the difficulty. Otherwise ... well, personally, if I didn't have such a strong commitment to faith, I probably would have left the organization." Although these programs do not target "refugees" per se, they address the ongoing needs of families affected by displacement. They strengthen self-reliance through psychosocial and legal assistance for individuals and families, in addition to supporting the efforts of women to organize in the struggle for political change and restitution. Over the past ten years, women's groups have made significant strides in locating disappeared family members, such as through policy changes regarding the submission of missing persons reports across country lines; organized caravans that search for lost loved ones; and international partnerships with forensic experts that facilitate the identification of remains through DNA testing. This case study is a prime example of how local faith actors can draw upon religious resources (e.g., spiritual capital, church infrastructure) to meet immediate psychological needs of families and bolster volunteer bases, while also promoting long-term change through civic engagement. Local actors are particularly well positioned to support organizing and advocacy efforts of local communities due to their profound commitment to their communities and deep understanding of the intricacies of these processes within the local context. Furthermore, they may not encounter the same types of institutional constraints that external organizations face in engaging in political activity.

In Mexico, La 72 also supports and promotes the self-reliance of displaced people and host communities through partnerships formed through a network of religious-based community organizations. Communities situated along the Gulf route leading to Tenosique have for years received high volumes of migrants in transit and, consequently, ongoing persecution by the authorities for even the smallest acts of migrant assistance. La 72 called upon church group leadership to organize the communities and equip them with the knowledge and skills necessary to aid migrants and to defend their own legal rights when targeted by police retribution. As one participant expressed: "Now we are able to protect ourselves and to tell [migration authorities] that they cannot enter our property because it is our property. ${ }^{5}$ And we have the backing of La 72 and the human rights, and with that we are able to protect ourselves."

La 72 draws upon religious beliefs and teachings to convey human rights principles and to generate empathy and solidarity among local residents with the migrants they assist. This type of committed labor does not rely on funding schemes or intervention by external organizations, but rather on the mutual support and ongoing dialogue between La 72 and the community organizations. Central to the partnership is the motivation and empathy that La 72 leaders are able to inspire in community members through a framework of religious and spiritual devotion.

La 72 works closely with the central parish in Tenosique to promote ... the Franciscan message of social justice and love for one's fellow man ... and the message that Jesus, too, was a migrant. To have a friar, someone with credibility in the eyes of the people, to preach at the pulpit these types of messages, is really important to shifting people's mentalities and breaking down their prejudice ... to help them see things differently.

As this quote implies, the efficacy and long-term potential of training and education practices depends on meaningful engagement of local residents, such as through culturally appropriate communication, incentives that align with the objectives and needs of local residents, and the trust and credibility of educators. 
As these case studies demonstrate, the intervention of local faith leaders and faith communities is critical to enhancing self-reliance in diverse contexts of integration, resettlement, and host community support. The self-reliance of displaced people is necessary for the sustainability of future solutions to complex and multiscalar dilemmas. However, this also requires a high level of volunteerism and activism among local residents and communities to fulfill unmet needs generated by a lack of state welfare or withdrawn assistance from the international community. While it is essential to recognize the efforts and advances of local actors and organizations that bolster community support and integration, this should not detract from critical inquiry into the role of more powerful institutions within global aid regimes. International aid organizations could play a much stronger role in supporting local actors to support the self-reliance of displaced people by assuming a more critical stance toward national governments and applying more external pressure to hold governments accountable for meeting the population's needs. Furthermore, as demonstrated in many of our case studies, it is paramount that local interventions that aim to build self-reliance include a social justice component that promotes the capacity of displaced people to protect their human rights and advocate for political change, along with the necessary material resources that make civic engagement possible. If self-reliance interventions are not linked to political solutions, the right to remain or return to one's country of origin cannot be fully realized (Chimni 2018).

Local faith actors are also to be seen as part of the inherent and ongoing self-reliance of displaced and host communities, occurring without, and even in spite of, external intervention. As part of the communities, local faith actors will continue to support the community even when others do not. Just as their own self-reliance is built on and supported by their personal faith and faith community, local faith actors are supporting those around them. This can make them vulnerable to instrumentalization or the overreliance from others that they will always be there to support the community.

\section{Conclusion}

We have seen the many ways in which local faith actors situated in countries that are often conceptualized as being part of the global South are involved in support for displaced people. This evidence helps further our understanding of LFAs and supports the more conceptual assertions around secular-faith divides, as linked to Northern-Southern divides. The work of LFAs includes spiritual and psychological support that represents innovative practice, conversations about religion and belief between displaced people and hosts, work on building appreciation of human rights and dignity, spreading knowledge and information, and filling the gaps where other services are lacking. The frameworks through which local faith actors discuss and conceptualize such practices complicates widely accepted notions of what constitutes good practices of refugee response as defined by the international humanitarian aid community. Innovation was not described in terms of technologically driven interventions or products, but rather as practices that promote personal resilience and inclusivity among displaced people. The innovative capacity of these practices lies in the ways that they target root causes of psychological distress and violence: by resisting stigma and challenging existing discriminatory cultural paradigms. This approach equips displaced people with new tools to build self-esteem, embrace identity, and recognize the sociostructural drivers of migration (rather than viewing it through an individualizing discourse).

Local faith leaders also provided a nuanced understanding of the role of faith and civic engagement in refugee assistance. Common humanitarian accounts tend to shy away from such 
topics in order to uphold values of impartiality and neutrality. Religion is avoided or actively rejected out of persistent qualms with questions of proselytization. Yet, as our findings revealed, an inclusive and ecumenical approach to spirituality can serve as a powerful means of crosscultural dialogue and relationship building. Similarly, local support for organizing and advocating for migrant and refugee rights and dignity is viewed as critical to the efforts of displaced people and their communities to build self-reliance and envision long-term change. Recognition of the intricacies of these processes within the local context, rather than the outright rejection of any religious- or civic-based practices, may foster innovative partnerships and create new opportunities for collaboration and cohesion throughout the community

The "othering" of local faith actors as "other local actors" working in "other relevant areas" is a limiting view that obscures a multitude of activities and nuance within those activities. Each area of analysis (innovation, proselytization, and self-reliance) has been shown to be problematic for local faith actors in that their activities and motivations are misrepresented if understood from a purely Northern viewpoint. From this perspective, the emphasis is put on contradictory points such as the viewpoint that local faith actors lack capacity, yet they should be self-reliant; that innovation comes from technological advances mainly in the global North, but that local actors demonstrate innovation too; and that local faith actors are problematic because they are prone to proselytization, yet with little appreciation of the nuance of religious expression and motivations. Generalizations and stereotypes from a Northern perspective categorize local faith actors in ways that our research has shown to be misleading. The power imbalance between North and South means that international actors have spent very little time considering local actors, let alone local faith actors, yet have rushed to categorize and generalize about them. This article has aimed to demonstrate how the theoretical discussions around faith in humanitarian response and North-South divides in international humanitarian processes meet with the reality of LFAs in refugee response as seen in empirical research. Our contribution is to demonstrate how Northern framings of policy processes such as the GCR and corresponding terminologies such as self-reliance and innovation are in tension with the experiences and relevant concepts used by LFAs.

\section{ACKNOWLEDGMENTS}

We thank UNHCR for support in primary research in Mexico and Honduras. The opinions in this article solely represent the views of the authors and do not represent the views of UNHCR or the other organizations involved.

HEATHER WURTZ is a Doctoral Candidate graduating in May 2020 in the Program in Sociomedical Sciences at Columbia University, with a joint PhD degree in Anthropology and Public Health. Her research interests center on migration and refugee studies; gender and sexuality; critical feminist geography; social movements and collective action; and the social impact of policy. Her geographic focus is on Mexico, Central America, and the United States. Email: hmw2129@columbia.edu

OLIVIA WILKINSON works at the intersection of sociology of religion and international humanitarian/development studies. She is Director of Research for the Joint Learning Initia- 
tive on Faith and Local Communities. She has a PhD from Trinity College Dublin, which has recently been published by Routledge titled "Secular and Religious Dynamics in Humanitarian Response." The book unpicks how secularity is one of many privileges and biases in the humanitarian system, making aid unfair and inappropriate. Email: olivia@jliflc.com

\section{NOTES}

1. See http://www.globalcrrf.org/what-is-a-good-practice/.

2. Definition of local actors in paragraph 37 of the GCR: "Local authorities and other local actors in both urban and rural settings, including local community leaders and traditional community governance institutions, are often first responders to large-scale refugee situations, and among the actors that experience the most significant impact over the medium term. In consultation with national authorities and in respect of relevant legal frameworks, support by the international community as a whole may be provided to strengthen institutional capacities, infrastructure and accommodation at local level, including through funding and capacity development where appropriate. Recruitment of local personnel by humanitarian and development agencies is encouraged in line with relevant laws and policies, while bearing in mind the need for continued capacity of local actors, organizations and structures."

3. Definition of faith-based actors in paragraph 41 of the GCR: "Faith-based actors could support the planning and delivery of arrangements to assist refugees and host communities, including in the areas of conflict prevention, reconciliation, and peacebuilding, as well as other relevant areas."

4. The Joint Learning Initiative launched a policy brief in December 2018 to coincide with the adoption of the GCR that goes through every section of the GCR to give examples from research that demonstrate the ways in which faith actors play a part in every element of the GCR; see https://jliflc.com/ resources/policy-brief-faith-actors-and-the-implementation-of-the-global-compact-on-refugees/.

5. Emphasis author's own.

\section{REFERENCES}

Ager, Alastair, and Joey Ager. 2015. Faith, Secularism, and Humanitarian Engagement: Finding the Place of Religion in the Support of Displaced Communities. New York: Palgrave Macmillan.

Ager, Joey, Elena Fiddian-Qasmiyeh, and Alastair Ager. 2015. "Local Faith Communities and the Promotion of Resilience in Contexts of Humanitarian Crisis." Journal of Refugee Studies 28 (2): 202-21. https://doi.org/10.1093/jrs/fev001.

Berger, Roni. 2015. "Now I See It, Now I Don't: Researcher's Position and Reflexivity in Qualitative Research." Qualitative Research 15 (2): 219-234. https://doi.org/10.1177/1468794112468475.

Chimni, B. S. 2018. "Global Compact on Refugees: One Step Forward, Two Steps Back." International Journal of Refugee Law 30 (4): 630-634.

Domicelj, Tamara, and Carolina Gottardo. 2019. "Implementing the Global Compacts: The Importance of a Whole-of-Society Approach." Forced Migration Review 60 (March). https://www.fmreview.org/ education-displacement/domicelj-gottardo.

Easton-Calabria, Evan, and Naohiko Omata. 2018. "Panacea for the Refugee Crisis? Rethinking the Promotion of 'Self-Reliance' for Refugees." Third World Quarterly 39 (8): 1458-1474. https://doi.org/ 10.1080/01436597.2018.1458301.

El Nakib, Shatha, and Alastair Ager. 2015. "Local Faith Community and Related Civil Society Engagement in Humanitarian Response with Syrian Refugees in Irbid, Jordan: Report to the Henry Luce Foundation." New York: Columbia University, Mailman School of Public Health. http://jliflc.com/ wp-content/uploads/2015/06/El-Nakib-Ager-Local-faith-communities-and-humanitarian-respo nse-in-Irbid-.pdf. 
Ensor, Marisa Olivo. 2003. "Disaster Evangelism: Religion as a Catalyst for Change in Post-Mitch Honduras." International Journal of Mass Emergencies and Disasters 21 (2): 31-49.

Ferris, E. 2011. "Faith and Humanitarianism: It’s Complicated." Journal of Refugee Studies, Vol. 24, No. 3, 606-25.

Fiddian-Qasmiyeh, Elena. 2011. “The Pragmatics of Performance: Putting 'Faith' in Aid in the Sahrawi Refugee Camps." Journal of Refugee Studies, Vol. 24, No. 3, 533-47.

Fiddian-Qasmiyeh, Elena. 2015. South-South Educational Migration, Humanitarianism and Development: Views from the Caribbean, North Africa and the Middle East. London: Routledge.

Fiddian-Qasmiyeh, Elena. 2018a. "Histories and Spaces of Southern-Led Responses to Displacement." Southern Responses to Displacement (blog), 16 July. https://southernresponses.org/2018/07/16/ histories-and-spaces-of-southern-led-responses-to-displacement/.

Fiddian-Qasmiyeh, Elena. 2018b. "The Localisation of Aid and Southern-Led Responses to Displacement." Refugee Hosts (blog), 17 April. https://refugeehosts.org/2018/04/17/the-localisation-of-aidand-southern-led-responses-to-displacement/.

Fiddian-Qasmiyeh, Elena. 2019. “The Changing Faces of UNRWA: From the Global to the Local." Journal of Humanitarian Affairs 1 (1): 28-41.

Fiddian-Qasmiyeh, Elena, and Patricia Daley, eds. 2018. Routledge Handbook of South-South Relations. London: Routledge.

Fiddian-Qasmiyeh, Elena, and Julia Pacitto. 2016. "Writing the Other into Humanitarianism: A Conversation between 'South-South' and 'Faith-Based' Humanitarianisms." In The New Humanitarians in International Practice: Emerging Actors and Contested Principles, ed. Zeynep Sezgin and Dennis Dijkzeul (282-300). London: Routledge.

Garred, Michelle, and Mohammed Abu-Nimer. 2018. Making Peace with Faith: The Challenges of Religion and Peacebuilding. Lanham, MD: Rowman \& Littlefield.

Gutiérrez, Gustavo. 1988. A Theology of Liberation: History, Politics, and Salvation. Maryknoll, NY: Orbis Books.

Hayward, Susan, and Katherine Marshall. 2015. Women, Religion, and Peacebuilding: Illuminating the Unseen. Washington DC: United States Institute of Peace.

Hurd, Elizabeth Shakman. 2015. Beyond Religious Freedom: The New Global Politics of Religion. Princeton, NJ: Princeton University Press.

Jayawickrama, Janaka, and Bushra Rehman. 2018. “Before Defining What Is Local, Let's Build the Capacities of Humanitarian Agencies.” Southern Responses to Displacement (blog), 17 April. https:// southernresponses.org/2018/04/17/before-defining-what-is-local-lets-build-the-capacities-ofhumanitarian-agencies/.

Kubai, Anne. 2018. “No Ugali, No Peace, No Life': Nexus of Religion and Human Security in Kenya." In African Intellectuals and the State of the Continent: Essays in Honor of Professor Sulayman S. Nyang, ed. Olayiwola Abegunrin and Sabella Abidde (110-129). Newcastle upon Tyne, UK: Cambridge Scholars Publishing.

Lynch, Cecelia, and Tanya Schwarz. 2017. "Humanitarianism's Proselytism Problem.” International Studies Quarterly 60 (4). https://www.isanet.org/Publications/ISQ/Posts/ID/5271/Humanitarian isms-Proselytism-Problem.

Marshall, Katherine. 2016. "Nagging Tensions Around Development and Proselytizing." Religious Freedom Institute, 12 July. https://www.religiousfreedominstitute.org/cornerstone/2016/7/12/ nagging-tensions-around-development-and-proselytizing.

Milner, James. 2016. When Norms Are Not Enough: Understanding the Principle and Practice of Burden and Responsibility Sharing for Refugees. Ontario: Centre for International Governance Innovation.

Parater, Lauren. 2015. "10 Ways to Innovate in Higher Education Emergencies." UNHCR Innovation Service, 3 July. https://www.unhcr.org/innovation/10-ways-to-innovate-in-higher-education-inemergencies/.

Parker, Ben. 2019. "Humanitarian Innovation Faces Rethink as Innovators Take Stock." The New Humanitarian, 20 March. https://www.thenewhumanitarian.org/analysis/2019/03/20/humani tarian-innovation-faces-rethink-innovators-take-stock. 
Sharpe, Marina. 2018. "The Global Compact on Refugees and Conflict Prevention in Africa: 'Root Causes' and Yet Another Divide." International Journal of Refugee Law 30 (4): 707-10. https:// doi.org/10.1093/ijrl/eey052.

Shannahan, Chris, and Laura Payne. 2016. "Faith-Based Interventions in Peace, Conflict and Violence: A Scoping Study." Coventry, UK: Joint Learning Initiative on Faith and Local Communities; Coventry University. http://peace-and-conflict.jliflc.com/resources/faith-based-interventionspeace-conflict-violence-scoping-study/.

Sullivan, Winnifred Fallers, Elizabeth Shakman Hurd, Saba Mahmood, and Peter G. Danchin, eds. 2015. Politics of Religious Freedom. Chicago: University of Chicago Press.

UNHCR (United Nations High Commissioner for Refugees). n.d. "Essays: UNHCR's Innovation in Review." https://www.unhcr.org/innovation-year-in-review/essays/ (accessed 10 April 2019).

UNHCR (United Nations High Commissioner for Refugees). 2017. "The 10-Point Plan in Action.” https://www.unhcr.org/the-10-point-plan-in-action.html.

UNHCR (United Nations High Commissioner for Refugees). 2018. "Global Impact on Refugees: Draft 2." 30 April. https://www.unhcr.org/events/conferences/5ae758d07/official-version-draft-2-globalcompact-refugees-30-april-2018.html.

USAID (United States Agency for International Development). 2019. “The Journey to Self-Reliance." Last updated 5 November. https://www.usaid.gov/selfreliance.

Wilkinson, Olivia. 2017. "Localizing Response to Humanitarian Need: The Role of Religious and FaithBased Organizations. Key Examples of Methods and Mechanisms for Engagement \& Recommendations for Action. Conference Summary." Colombo, Sri Lanka: Joint Learning Initiative on Faith and Local Communities. https://lrf2017.org/reports/.

Wilkinson, Olivia, and Joey Ager. 2017. "Scoping Study on Local Faith Communities in Urban Displacement: Evidence on Localisation and Urbanisation.” Washington D.C.: Joint Learning Initiative on Faith and Local Communities.

Wilkinson, Olivia. 2018a. "Secular Humanitarians and the Postsecular: Reflections on Habermas and the Typhoon Haiyan Disaster Response." Journal of Contemporary Religion 33 (2): 193-208. https:// doi.org/10.1080/13537903.2018.1469260.

Wilkinson, Olivia J. 2018b. “It's Being, Not Doing': Hospitality and Hostility between Local Faith Actors and International Humanitarian Organizations in Refugee Response." Migration and Society 1 (1): 111-26. https://doi.org/10.3167/arms.2017.010110.

Wilson, Erin K. 2012. After Secularism: Rethinking Religion in Global Politics. Basingstoke, UK: Palgrave Macmillan.

Wilson, Erin K. 2017. "The Socio-Political Dynamics of Secularism and Epistemological Injustice in Global Justice Theory and Practice." European Societies 19 (5): 529-550. https://doi.org/10.1080/146 16696.2017.1334948.

World Humanitarian Summit. 2016. "Charter for Faith-Based Humanitarian Action." Istanbul: United Nations. https://www.agendaforhumanity.org/initiatives/4012. 